(Tsuru T, Mori M, Mizuguchi M, Momoi MY. Effects of high-dose intravenous corticosteroid therapy in Landau-Kleffner syndrome. Pediatr Neurol 2000;22:145147). (Respond: Dr Tsuru, Department of Pediatrics, Jichi Medical School, Kawachi-gun, Tochigi 329-0498, Japan).

COMMENT. High-dose corticosteroid therapy, administered early at the first appearance of symptoms, has been recommended in previous reports (Marescaux C et al. Epilepsia 1990;31:768-777; Lerman P et al. Dev Med Child Neurol 1991;33:257266; Progress in Pediatric Neurology II, PNB Publ, 1994;pp221-226).

\title{
LOW-DOSE CLONAZEPAM EFFECT ON EPILEPTIFORM ACTIVITY
}

The effect of low-dose clonazepam (CZP) on 24-hour long-term EEG recordings in 15 children with epilepsy was evaluated at the Karolinska Hospital, Stockholm, Sweden. A single IM injection of $0.02 \mathrm{mg} / \mathrm{kg} / \mathrm{bwt}$ produced a highly significant decrease in epileptiform activity compared to placebo, in a doubleblind study. Frequency of seizures decreased in parallel with the beneficial EEG response. Median plasma concentrations of CZP ranged from 18-<14 nM. (Dahlin M, Knutsson E, Amark P, Nergardh A. Reduction of epileptiform activity in response to low-dose clonazepam in children with epilepsy: A randomized doubleblind study. Epilepsia March 2000;41:308-315). (Reprints: Dr M Dahlin, Neuropediatric Department, Astrid Lindgren's Children's Hospital, Karolinska Hospital, S-171 76 Stockholm, Sweden).

COMMENT. Low-dose clonazepam therapy $(<0.02 \mathrm{mg} / \mathrm{kg} /$ day $)$ can be effective in the control of focal and generalized epilepsy, while reducing the incidence of side effects commonly occurring with higher conventional doses $(0.05 \mathrm{mg} / \mathrm{kg} / \mathrm{d})$. The development of tolerance is one of the greatest drawbacks of clonazepam therapy from a practical standpoint, an effect that usually leads to the necessity for larger doses and the occurrence of sedation, bronchial hypersecretion, and hyperactivity.

\section{NEUROFIBROMATOSIS}

\section{MAGNETIC RESONANCE STUDIES IN NEUROFIBROMATOSIS 1}

Nine patients with neurofibromatoisis type 1 (age, 6-19 years) and 9 controls were studied by quantitative magnetic resonance spectroscopic imaging (MRSI) at Johns Hopkins University School of Medicine, Baltimore, MD. Supratentorial UBO functional significance was studied using maps of the distribution of metabolites choline (Cho), N-acetylaspartate (NAA), and creatine. Metabolite concentrations were elevated or preserved in both UBOs and thalami of younger subjects ( $<10$ years) and normal or reduced in older subjects. Decreases in NAA ratios were greatest in thalami of subjects with UBOs in the globus pallidus. (Wang PY, Kaufmann WE, Koth CW, Denckla MB, Barker PB. Thalamic involvement in neurofibromatosis type 1: Evaluation with proton magnetic resonance spectroscopic imaging. Ann Neurol April 2000;47:477-484). (Respond: Dr Barker, Department of Radiology, MRI 143C, Johns Hopkins University School of Medicine, $600 \mathrm{~N}$ Wolfe St, Baltimore, MD 21287).

COMMENT. The authors postulate that thalamic choline elevations in younger patients with NF-1 may reflect an increased myelin turnover in areas of intramyelinic edema, followed by neurophil injury and reduced $\mathrm{N}$-acetylaspartate levels in older subjects. 